\title{
Vertebral end-plate lesions (Schmorl's nodes) in the dorsolumbar spine
}

\author{
R. C. HILTON, J. BALL, AND R. T. BENN \\ From the Department of Rheumatology, and the Arthritis and Rheumatism Council Epidemiology Research Unit, \\ University of Manchester
}

\begin{abstract}
Hilton, R. C., Ball, J., and Benn, R. T. (1976). Annals of the Rheumatic Diseases, 35, 127-132. Vertebral end-plate lesions (Schmorl's nodes) in the dorsolumbar spine. The distribution of end-plate lesions (Schmorl's nodes) and their relationship to bone density and disc degeneration have been studied in 50 post-mortem spines below D9 in subjects aged 13-96 years. Lesions were present in $76 \%$ of cases with a predominance in males. They were found more frequently in the lower than in the upper vertebral end-plate. They were also more common and more severe in the dorsolumbar (D10-L1) region than in the lower lumbar (L2-L5 region). In adults they were unrelated to age and bone density. Lesions were significantly related to disc degeneration in the D10-L1 region but not in the L2-L5 region. It is suggested that end-plate lesions arising in adolescence (or before) may predispose the dorsolumbar spine to disc degeneration in later life.
\end{abstract}

Since Schmorl (1927) and Putschar (1927) independently described the lesions variously known as Schmorl's nodes, cartilaginous nodes, intraspongious discal herniae (and here referred to as end-plate lesions-EPL), they have received little attention. Their pathogenesis is uncertain, and we remain ignorant of their relationships to other structural defects of the spine and to overall spinal function. We have therefore undertaken a systematic study of the spine below D9, and here report our findings on the distribution of EPL and their relationship to disc degeneration (DD) and bone density.

\section{Material and methods}

Fifty post-mortem specimens of the whole spine below D9 together with the sacrum have been studied. Subjects with neoplastic disease, gross osteoporotic vertebral collapse, and those who had received prolonged corticosteroid therapy were excluded. The age range was 13-96 years. There were 33 males (mean age 51.6 years) and 17 females (mean age $48 \cdot 3$ years). In each case undecalcified sections of a sacral bone block were examined for Paget's disease, osteomalacia, and other occult bone diseases except osteoporosis (see below). Only 3 subjects were found to be abnormal: a female aged 68 and a male aged 63 who had clinically unsuspected osteomalacia, and a male aged 42 who had moderately excessive osteoclastic bone resorption, probably secondary to renal disease.
These three cases were not excluded because the findings in their spines tended to minimize rather than enhance the significance of the main conclusions of the study.

\section{BONE DENSITY}

Vertebral bone density was assessed by measuring the weight/volume ratio of a complete central sagittal slab of the 3rd lumbar vertebra. After maceration the specimen was dried to constant weight in vacuo over phosphorus pentoxide. It was then embedded in wax and its volume measured using a pyknometer after the method of Atkinson and Woodhead (1968).

EPL AND DD (Figs. 1 and 2)

After removing the neural arches the vertebral bodies were divided into five sagittal slabs. Radiographs of these were graded for EPL and DD by two of the authors working together. Discs were identified by the vertebra above. Initially all suspect radiological abnormalities were studied histologically, a total of 123 sections from 37 cases being examined. On this basis EPL were defined radiologically as a discontinuity in the cartilaginous part of the vertebral end-plate (the part enclosed within the vertebral rim) associated with a translucency in the adjacent vertebral body. The lesions were graded on a $0-3$ scale according to the size and depth of the lesion. At each disc the grades for lesions of the upper and lower vertebral plates were recorded and added; thus the maximum EPL score (the severest grade) for each disc was 6. DD was assessed by grading disc narrowing and osteophytes separately on a 


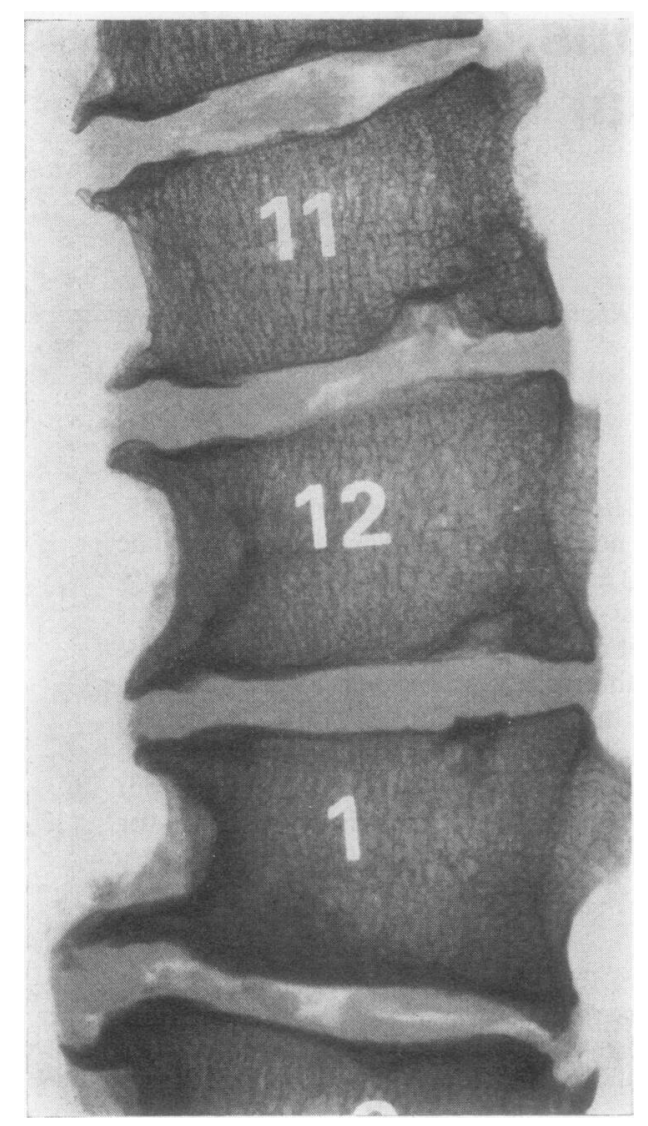

FIG. 1 Slab section showing grades of EPL, osteophytes, and disc narrowing

0-3 scale and adding the two grades. Thus the maximum grade for DD was 6 . Osteophytes were graded according to size. A disc was considered to be narrowed if its height was less than discs above.

\section{Results}

FREQUENCY AND DISTRIBUTION OF EPL EPL were found in 38 of the 50 cases $(76 \%)$. Many of the lesions seen in the slab radiographs are not clearly delineated in routine lateral or anteroposterior $x$-rays of the whole spine taken after removal from the body (Fig. 2). In only one case (a male aged 54) did the radiographs suggest a possible diagnosis of old Scheuermann's disease (Fig. 1). Though variable in size and shape, EPL are almost exclusively found in the central and posterocentral part of the end-plate (Figs. 1 and 2). They occur at more than one disc level in $66 \%$ of the total cases and $87 \%$ of cases with EPL(Figs. 3a and 4a). There is a tendency for adjacent discs in the D10-L1 region to be affected, as evidenced by positive correlations $(+0.34$ to +0.80$)$ between EPL scores at adjacent levels.
Table I shows that lesions are most commonly found at D10 and D11 discs, the prevalence falling slightly at D12 and $\mathrm{L} 1$ and progressively more rapidly at lower levels. They are more frequent in males than females at all disc levels but especially in the L2-L5 region; in males $37.8 \%$ of the discs examined had EPL compared with $23.5 \%$ in females $(0 \cdot 10>P>0.05)$. EPL are significantly more frequent in the D10-L1 region than in the L2-L5 region $(P<0.001)$. Their frequency does not increase with age in males (Table II, Figs. 3a and 4a); in females the increased frequency is not statistically significant. When the number of affected discs in each spine is plotted against age, again no relationship with age is found.

The severity of EPL is greater in the D10-L1 region (Table III, Figs. $3 a$ and $4 a$ ) where $44 \%$ of the EPL are graded 3 or more compared with only $21 \%$ in the L2-L5 region. The more severe EPL are also more frequent in males though the difference is not significant (Table III, Figs. 3a and 4a).

In the D10-L1 region (Table IV) EPL are commoner in the lower vertebral end-plate (upper border of the disc) than in the upper vertebral end-plate (lower border of the disc) in males $(P<0.01)$ and females $(0 \cdot 1>P>0.05)$. In the L2-L5 region this difference is not apparent in males, and in females the number with lesions is too small to allow conclusions.

RELATION OF EPL TO BONE DENSITY

Measurements of bone density show the expected relationship with age. When the total EPL score for each of the 50 specimens is plotted against bone density no association is found $(r=0.08$ in males and 0.07 in females). This finding agrees with the above observation that EPL are not age related.

RELATION OF EPL TO DISC DEGENERATION

In the D10-L1 region disc degeneration is more frequent in discs with end-plate lesions $(49 \%)$ than in discs without lesions $(20.8 \%)$ (Table V, Figs. 3b and $4 \mathrm{~b}$ ). In this region (D10-L1) there is a positive correlation between the scores for disc degeneration and EPL at each disc level in both sexes (Table VI). Between L2 and L5 there were insufficient EPL to allow analysis. In the L2-L5 region the overall prevalence of disc degeneration is about the same as in the D10-L1 region but there is no predilection for discs with end-plate lesions (Table V, Figs. 3b and 4b).

The relationship between EPL and disc degeneration in the D10-L1 region is age dependent (Table V). In the $<50$ age group, $24.4 \%(11 / 45)$ of discs with EPL had disc degeneration compared with $7.8 \%$ $(4 / 51)$ of discs without EPL. In the $\geqslant 50$ age group disc degeneration is found in $68.4 \%(39 / 57)$ of discs with EPL compared with $35 \cdot 6 \%(16 / 45)$ without EPL. 


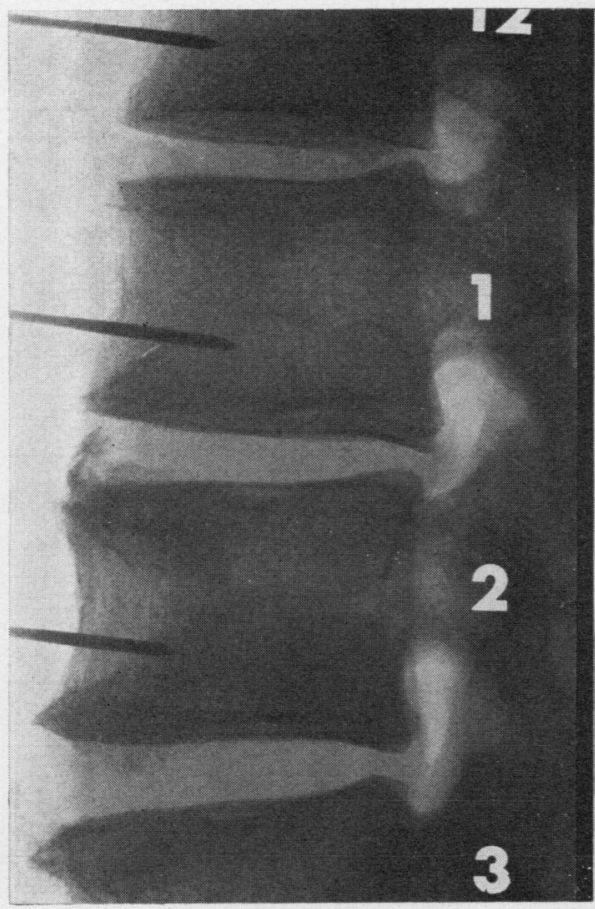

(a)

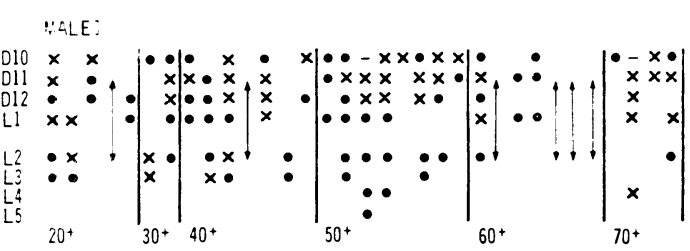

(a)

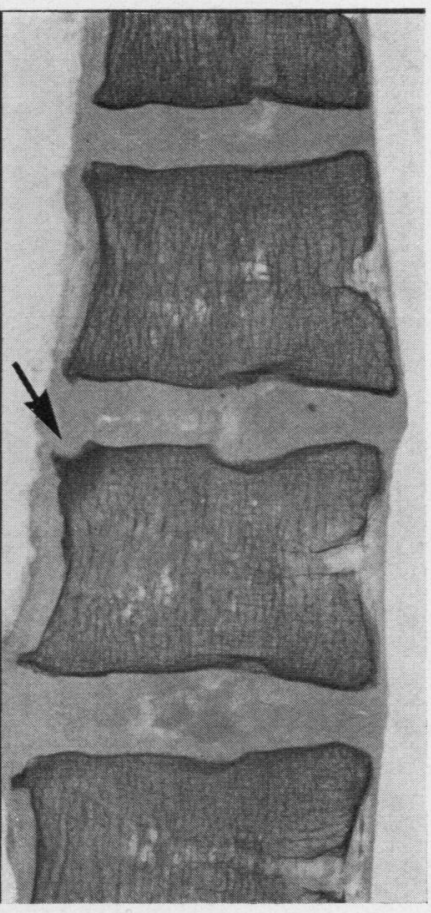

(b)
FIG. 2 (a) Post-mortem $x$-ray of D12-L3. (b) Sagittal slab of (a) showing much clearer delineation of EPL in each disc. Arrow points to a rim lesion

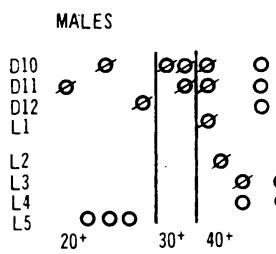

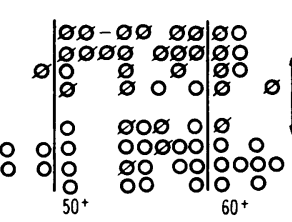

(b)

FIG. 3 (a) EPL in individual males by age (decade), disc level, and grade. $\bullet=E P L$ severity $<3 ; \mathbf{X}=E P L$ severity $\geqslant 3 ;$ - indicates not examined; vertical arrow indicates patient with no EPL. (b) DD in individual males by age (decade), disc level, and $E P L . O=D D+$ disc; $\varnothing=D D+E P L+$ disc; - indicates not examined; vertical arrow indicates patient with no $D D$

In Fig. 5 the mean score for disc degeneration in discs with and without EPL in the D10-L1 region is plotted for four age groups. It can be seen that the mean score for disc degeneration is higher in discs with EPL in each age group and the difference increases with age. Thus in the D10-L1 region, disc degeneration is not only more frequent but may have an earlier onset in discs with EPL.

\section{Discussion}

Schmorl and Junghanns (1971) recognized that intraspongious discal herniations (Schmorl's nodes) could be due to trauma, tumour, or various forms of metabolic bone disease, but that in many cases these factors were absent and the cause remained speculative. In the present study we have selected spines in which any Schmorl's nodes detected were likely to be of the idiopathic variety. Since histological study showed that the nodes in our cases were invariably associated with a gap in the cartilaginous end-plate we have used the term end-plate lesion (EPL). Studying serial slab radiographs of the spine below D9 we found EPL in $76 \%$ of 50 cases. This is twice the prevalence recorded by Schmorl and Junghanns (1971).

We find that EPL are significantly more frequent and generally more severe in the $\mathrm{D} 10-\mathrm{L} 1$ region than in the L2-L5 region. This frequency distribution agrees with the findings of Putschar (1927) in the 


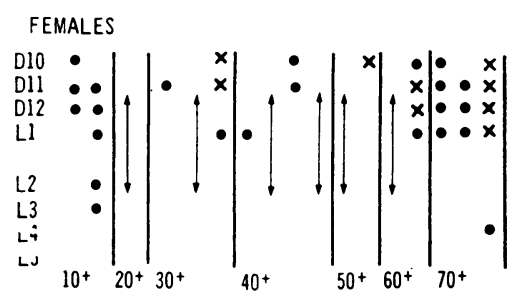

(a)

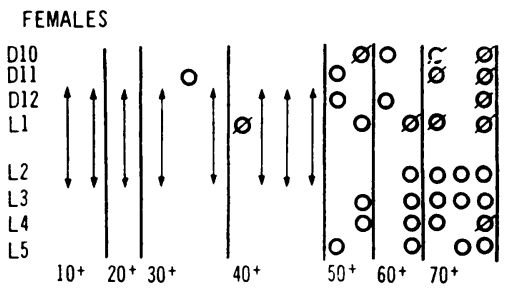

(b)

FIG. 4 (a) EPL in individual females by age (decade), disc level, and grade. $\bullet=E P L$ severity $<3 ; \mathrm{X}=E P L$ severity $\geqslant 3$; vertical arrow indicates patient with no EPL. (b) $D D$ in individual females by age (decade), disc level, and $E P L . \bigcirc=D D+$ disc $; \varnothing=D D+E P L+$ disc , vertical arrow indicates patient with no $D D$

Table I Prevalence of EPL + discs (\%) at each disc level in 33 males and 17 females

\begin{tabular}{|c|c|c|c|}
\hline Disc level & Males & Females & Total \\
\hline $\begin{array}{l}\text { D } 10 \\
\text { D } 11 \\
\text { D } 12 \\
\text { L } 1\end{array}$ & $\begin{array}{l}65 \\
61 \\
48 \\
52\end{array}$ & $\begin{array}{l}41 \\
53 \\
35 \\
41\end{array}$ & $\begin{array}{l}56 \\
58 \\
44 \\
48\end{array}$ \\
\hline $\begin{array}{l}\text { L } 2 \\
\text { L } 3 \\
\text { L } 4 \\
\text { L } 5\end{array}$ & $\begin{array}{r}42 \\
24 \\
9 \\
3\end{array}$ & $\begin{array}{l}6 \\
6 \\
6 \\
0\end{array}$ & $\begin{array}{r}32 \\
18 \\
8 \\
2\end{array}$ \\
\hline D 10-L 5 & $37 \cdot 8^{*}$ & $23 \cdot 5^{*}$ & $32 \cdot 9$ \\
\hline
\end{tabular}

$* 0.1>P>0.05$.
Table II Prevalence of EPL+ discs (\%) by age group, sex, and spinal region

\begin{tabular}{|c|c|c|c|c|}
\hline \multirow{2}{*}{$\begin{array}{l}\text { Spinal } \\
\text { region }\end{array}$} & \multirow{2}{*}{$\begin{array}{l}\text { Age group } \\
\text { (years) }\end{array}$} & \multicolumn{3}{|c|}{$E P L+d i s c s$} \\
\hline & & Males & Females & Total \\
\hline D $10-\mathrm{L} 1$ & $\begin{array}{l}<50 \\
\geqslant 50\end{array}$ & $\begin{array}{l}57 \\
55\end{array}$ & $\begin{array}{l}33 \\
57\end{array}$ & $\begin{array}{l}47 \\
56\end{array}$ \\
\hline Total & & 56 & 43 & $52^{*}$ \\
\hline L 2-L 5 & $\begin{array}{l}<50 \\
\geqslant 50\end{array}$ & $\begin{array}{l}23 \\
17\end{array}$ & $\begin{array}{l}5 \\
4\end{array}$ & $\begin{array}{l}14 \\
13\end{array}$ \\
\hline Total & & 20 & 4 & $15^{*}$ \\
\hline
\end{tabular}

$* \mathrm{P}<0.001$.

Table III Distribution of EPL + discs (\%) by grade of severity, sex, and spinal region

\begin{tabular}{|c|c|c|c|c|c|c|}
\hline \multirow{3}{*}{$\begin{array}{l}\text { Spinal } \\
\text { region }\end{array}$} & \multicolumn{6}{|c|}{ EPL grade } \\
\hline & \multicolumn{3}{|l|}{$\overline{1-2}$} & \multicolumn{3}{|l|}{$3-6$} \\
\hline & Male & Female & Total & Male & Female & Total \\
\hline $\begin{array}{l}\text { D 10-L } 1 \\
\text { L } 2-L 5\end{array}$ & $\begin{array}{l}51 \\
77\end{array}$ & $\begin{array}{r}69 \\
100\end{array}$ & $\begin{array}{l}56 \\
79\end{array}$ & $\begin{array}{l}49 \\
23\end{array}$ & $\begin{array}{r}31 \\
0\end{array}$ & $\begin{array}{l}44 \\
21\end{array}$ \\
\hline
\end{tabular}

Table IV Distribution of EPL (no.) by sex and vertebral end-plate, at disc levels D10-LI

\begin{tabular}{|c|c|c|c|c|c|c|}
\hline \multirow[t]{2}{*}{ Disc level } & \multicolumn{3}{|c|}{ Lower plate } & \multicolumn{3}{|c|}{ Upper plate } \\
\hline & Male & Female & Total & Male & Female & Total \\
\hline $\begin{array}{l}\text { D } 10 \\
\text { D } 11 \\
\text { D } 12 \\
\text { L } 1\end{array}$ & $\begin{array}{l}19 \\
20 \\
14 \\
15\end{array}$ & $\begin{array}{l}7 \\
9 \\
6 \\
5\end{array}$ & $\begin{array}{l}26 \\
29 \\
20 \\
20\end{array}$ & $\begin{array}{r}15 \\
13 \\
11 \\
9\end{array}$ & $\begin{array}{l}5 \\
5 \\
4 \\
4\end{array}$ & $\begin{array}{l}20 \\
18 \\
15 \\
13\end{array}$ \\
\hline Total & $68^{*}$ & $27 \dagger$ & 95 & $48^{*}$ & $18 \dagger$ & 66 \\
\hline
\end{tabular}

$+0.1>P>0.05$

Table V Distribution of DD in EPL + and EPL - discs by age group and spinal region

\begin{tabular}{|c|c|c|c|c|c|c|c|}
\hline \multirow[t]{2}{*}{ Spinal region } & \multirow[t]{2}{*}{ Age (years) } & \multirow[t]{2}{*}{$E P L+$ discs } & \multicolumn{2}{|c|}{$D D$ in $E P L+$} & \multirow[t]{2}{*}{$E P L-$ discs } & \multicolumn{2}{|c|}{$D D$ in $E P L-$} \\
\hline & & & No. & $(\%)$ & & No. & $(\%)$ \\
\hline D 10-L 1 & $\begin{array}{l}<50 \\
\geqslant 50\end{array}$ & $\begin{array}{l}45 \\
57\end{array}$ & $\begin{array}{l}11 \\
39\end{array}$ & $\begin{array}{l}(24 \cdot 4) \\
(68 \cdot 4)\end{array}$ & $\begin{array}{l}51 \\
45\end{array}$ & $\begin{array}{r}4 \\
16\end{array}$ & $\begin{array}{l}(7 \cdot 8) \\
(35 \cdot 6)\end{array}$ \\
\hline Total & & 102 & 50 & $(49 \cdot 0)$ & 96 & 20 & (20.8) \\
\hline L 2-L 5 & $\begin{array}{l}<50 \\
\geqslant 50\end{array}$ & $\begin{array}{l}15 \\
14\end{array}$ & $\begin{array}{l}2 \\
8\end{array}$ & $\begin{array}{l}(13 \cdot 3) \\
(57 \cdot 1)\end{array}$ & $\begin{array}{l}81 \\
90\end{array}$ & $\begin{array}{r}8 \\
53\end{array}$ & $\begin{array}{r}(9 \cdot 8) \\
(58 \cdot 8)\end{array}$ \\
\hline Total & & 29 & 10 & $(34 \cdot 4)$ & 171 & 61 & $(35 \cdot 6)$ \\
\hline
\end{tabular}


Table VI Partial correlation coefficients with age adjustment of EPL and disc degeneration scores

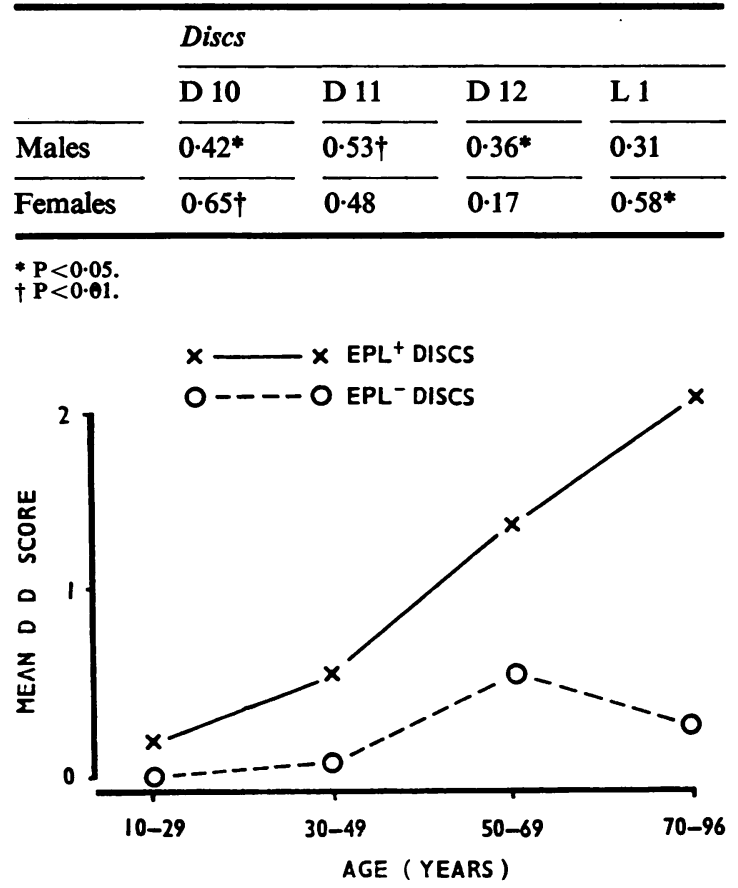

FIG. 5 Mean DD score for EPL -, and EPL + discs in the D10-L1 region plotted against age

D11-L2 region and those of Begg (1954) in the L1-L5 region. Curiously Schmorl and Junghanns do not mention this regional difference. The predominance of EPL in the D10-L1 region as compared with the L2-L5 region remains unexplained. Since vertebral fractures most commonly occur at the D12 and L1 levels (Jefferson, 1927; Nicoll, 1949) the D10-L1 region may be relatively susceptible to stress. Vertebral fractures, however, usually involve the upper end-plate (lower border of disc) preferentially (Howorth, 1956; Schinz and others, 1952) whereas, as we have shown, EPL occur most frequently in the lower end-plate. It is unlikely therefore that the distribution of EPL is based simply on differences in the distribution of stress in the spine below D9.

According to Putschar (1927) and Schmorl and
Junghanns (1971) EPL occur in the late teens. Our observations confirm this and suggest that the frequency does not increase with age since the incidence of EPL was similar in patients $<50$ and $\geqslant 50$ years of age. This latter observation agrees with our finding that the frequency of EPL is unrelated to vertebral bone density.

Microfractures as described by Vernon-Roberts and Pirie (1973), though tending to accumulate around EPL are unlikely to be responsible for the development of EPL in our material, since unlike EPL they increase in frequency with age, show a direct relationship to osteoporosis, and increase in frequency from $\mathrm{L} 1$ to $\mathrm{L} 4$.

The finding of a relationship between EPL and disc degeneration was unexpected. Our observations suggest that whereas disc degeneration occurs at all levels below $\mathrm{D} 9$, its presence in the $\mathrm{D} 10-\mathrm{L} 1$ region is in some way related to the presence of EPL. Since EPL are already present during skeletal maturation they are unlikely to be the result of disc degeneration. In subjects under 50 years disc degeneration in the D10-L1 region is already more frequent in discs with EPL than in those without; and after 50 years this difference becomes even more marked. It is therefore possible that in the D10-L1 region of the spine EPL originating in childhood or adolescence, both predispose to disc degeneration and cause its earlier onset.

The possible mechanisms involved are unknown but it is relevant to recall that the physical attributes of a disc are altered in those affected by EPL (Nachemson, 1960). In the L2-L5 region EPL appear to have little or no pathogenetic role since disc degeneration is common in their absence.

At all levels below D9 EPL were more frequent in males than females. Indeed below $L 1$ they were extremely rare in females. The reason for the male preponderance is presently unknown. Considering that EPL are a prominent (perhaps even the essential) lesion of Scheuermann's disease (Schmorl and Junghanns, 1971), which also occurs mainly in males and characteristically affects the lower dorsal spine, it may be that this disease is an unusually severe expression of the very common but usually clinically occult spinal defect encountered in the present study.

We thank Professor J. H. Kellgren for his encouragement and advice during the preparation of this paper.

\section{References}

Atkinson, P. J., AND WoodheAd, C. (1968) Arch. oral Biol., 13, 1453 (Changes in human mandibular structure with age)

BEGG, A. C. (1954) J. Bone Jt Surg., 36B, 180 (Nuclear herniations of the intervertebral disc. Their radiological manifestations and significance)

HowORTH, M. B. (1956) Amer. J. Surg., 92, 573 (Fracture of the spine)

Jefrerson, G. (1927) Proc. roy. Soc. Med., 21, 625 (Discussion on spinal injuries)

NACHEMson, A. (1960) Acta orthop. scand., Suppl. 43, 1 (Lumbar intradiscal pressure. Experimental studies on post mortem material) 
NiColl, E. A. (1949) J. Bone Jt Surg., 31B, 376 (Fractures of the dorso-lumbar spine)

PutsChaR, W. (1927) Beitr. path. Anat., 79, 150 (Zur Kenntniss der knorpelinseln in den wirbelkörpern)

SChinz, H. R., BaENSCH, W. E., FriedL, E., AND Uehlinger, E. (1952) In 'Roentgen-Diagnostics', 1st American edition, Vol. 2, p. 1547. Heinemann, London

SCHMORL, G. (1927) Verh. dtsch. path. Ges., 22, 250 (Über die an den wirbelbandscheiben vorkommenden ausdehnungs-und zerreisungsvorgänge und die dadurch an ihnen und der wirbelspongiosa hervorgerufenen veränderungen)

- , AND JunghanNs, H. (1971) In 'The Human Spine in Health and Disease', 2nd American edition. Grune and Stratton, New York and London

Vernon-Roberts, B., ANd Pirie, C. J. (1973) Ann. rheum. Dis., 32, 406 (Healing trabecular microfractures in the bodies of lumbar vertebrae) 